\title{
Aquagenic urticaria: diagnostic and management challenges
}

This article was published in the following Dove Press journal:

Journal of Asthma and Allergy

29 November 2016

Number of times this article has been viewed

\section{Robert Rothbaum Jean S McGee}

Department of Dermatology, Boston University School of Medicine, Boston, MA, USA
Correspondence: Jean S McGee Department of Dermatology, Boston University School of Medicine, 609 Albany Street, Boston, MA 02II8, USA Email jeanmcgee@gmail.com
Abstract: Aquagenic urticaria $(\mathrm{AU})$ is a rare inducible form of physical urticaria, which occurs in response to cutaneous exposure to water, including sweat and tears. Patients present with characteristic 1-3 mm folliculocentric wheals with surrounding 1-3 cm erythematous flares within 20-30 minutes following skin contact with water. In rare cases, there are concomitant systemic symptoms, such as wheezing or shortness of breath. The pathogenesis of AU is poorly understood at this time, and it appears to be mediated in both a histamine-dependent and independent manner. Diagnosis is based on eliciting a thorough clinical history combined with a water challenge test. Some patients may need to undergo further testing to exclude other physical urticarias. Rarely, multiple physical urticarias can be present in one patient, which can complicate diagnosis and treatment. Currently, the first-line therapy for AU is an oral administration of nonsedating, second-generation $\mathrm{H}_{1}$ antihistamines, but many patients may require further interventions to have adequate symptomatic control. In this review, we discuss the diagnostic and management challenges of AU. We review the key diagnostic features that differentiate AU from other physical urticarias. We additionally describe a therapeutic ladder for the treatment of AU and the rationale supporting these treatments.

Keywords: aquagenic urticaria, physical urticaria, inducible urticaria, diagnosis, management

\section{Introduction}

Water is ubiquitous in our daily lives and generally regarded as harmless, yet for some patients, water is a source of great discomfort. Aquagenic urticaria (AU), a form of physical urticaria that occurs with cutaneous exposure to water, including sweat and tears, was first described in the literature in 1964 by Shelley and Rawnsley. ${ }^{1}$ The latest World Allergy Organization guidelines on urticaria now classify AU as an inducible type of chronic urticaria, whereas this condition and other physical urticarias were previously grouped together due to their inducible nature by specific physical stimuli. ${ }^{2}$ In this review, we will use both terms, inducible urticaria and physical urticaria, synonymously to describe AU. While AU is very rare, with 50 cases reported in the literature at the time of writing this review, it causes significant morbidity for affected patients.

Among the limited cases reported in the literature, there seems to be a higher prevalence among females with the disease onset typically occurring during puberty or postpuberty. However, there have been reports of childhood-onset disease. ${ }^{3}$ While most cases seem to be sporadic in nature, there have been several case reports of familial disease. ${ }^{4-6}$ One familial cohort presented with coexistent Bernard-Soulier syndrome in the affected patients, raising the possibility of an associated genetic locus for $\mathrm{AU}$; 
however, no specific gene or locus for AU has been identified thus far. ${ }^{7} \mathrm{AU}$ has also rarely been reported in association with systemic conditions, including HIV infection, and occult papillary carcinoma of the thyroid gland.,

The mechanism of AU is poorly understood. In the 1960s, Shelley and Rawnsley were the first to propose a mechanism; they hypothesized that water reacts with sebum or sebaceous glands to form a toxic substance, which stimulates mast cell degranulation and subsequent histamine release, leading to the development of urticarial lesions. ${ }^{1}$ In 1981, Tkach hypothesized that the mechanism of AU has to do with sudden changes in osmotic pressure surrounding hair follicles, leading to increased passive diffusion of water. ${ }^{10}$ This sudden change in the pressure results in indirect provocation of urticaria. More recently, Gallo et al have described cases of localized AU following epilation, which seem to corroborate Tkach's hypothesis. ${ }^{11,12}$ Another proposed mechanism involves existence of water-soluble antigens in the epidermis, which dissolves and diffuses across the dermis with resulting histamine release. ${ }^{13}$ A more recent study by Luong and Nguyen in 1998, however, suggests a mechanism that may be completely independent of histamine release; they reported several patients with $\mathrm{AU}$ who exhibited no increase in histamine levels upon exposure to water, which was sufficient to induce urticaria. ${ }^{3}$ Depending on the sensitivity of the assay used, a rise in the plasma histamine level may not have been sufficiently detected in these patients. Regardless, a histamine-independent mechanism is still conceivable based on the observation that pretreatment with scopolamine (acetylcholine antagonist) prior to contact with water can suppress wheal formation. ${ }^{14}$ The lack of a clear pathogenesis for AU has contributed to difficulty in proposing evidence-based treatments for affected patients.

\section{Clinical presentation}

Patients with AU will present with characteristic 1-3 $\mathrm{mm}$ folliculocentric wheals and surrounding $1-3 \mathrm{~cm}$ erythematous flares within 20-30 minutes following skin contact with water. ${ }^{1}$ Patients can also experience associated symptoms, including pruritus, burning, and uncomfortable prickling. ${ }^{1}$ Urticarial lesions will typically resolve within 30-60 minutes of cessation of water contact with the skin. Lesions most commonly appear on the trunk and upper arms, usually sparing the palms and soles. The affected areas are generally refractory to repeated stimulations for several hours. Rarely, patients can experience systemic symptoms such as wheezing or shortness of breath. ${ }^{3,8}$

There are also some uncommon clinical presentations of AU. While urticaria is thought to occur in response to any form of water in $\mathrm{AU}$, there have been reports of patients who have had reactions depending on the salinity of the water. For example, a patient reacted to tap water, snow, and sweat, but could still swim in the ocean without urticaria. ${ }^{11,15}$ In patients who have decreased thickness of the stratum corneum following epilation or cutaneous exposure to organic solvents, there can be an exaggerated urticarial response to water. ${ }^{3,10}$ Additionally, in AU patients with associated systemic disease, the urticarial response seems to be often more dramatic, consisting of large edematous plaques rather than the classic punctate perifollicular wheals. ${ }^{8,9}$

\section{Diagnostic challenges}

Diagnosis of AU is largely based on a history of recurrent urticaria after exposure to water combined with a water challenge test. The test can be administered in a variety of ways; however, the standard method is to apply water at room temperature to a cloth and apply this damp cloth to the patient's skin for 20 minutes, with an urticarial reaction indicating a positive test. ${ }^{2}$ The temperature of water applied to the patient's skin is important because significant heat or cold exposure can potentially induce other physical urticarias, giving a falsepositive result. A physical examination should also focus on testing for dermatographism and searching for any systemic signs such as wheezing. On laboratory evaluation, the level of serum immunoglobulin E should be normal, which can help to differentiate $\mathrm{AU}$ from immunoglobulin E-mediated allergic reaction. When patients present with angioedema along with urticaria, it might be helpful to investigate the etiology of angioedema by checking the level of C1-esterase inhibitor. Hereditary and acquired angioedema present with angioedema only and the level of functional C1-esterase inhibitor should be normal. It is important to note that the serum histamine levels may or may not be elevated following exposure to water. ${ }^{3}$ Finally, the histopathology of $\mathrm{AU}$ is consistent with nonspecific urticaria; therefore, it does not play a role in guiding the diagnosis.

The main challenge in diagnosing AU lies in differentiating this condition from other types of physical urticaria (eg, cholinergic urticaria, heat urticaria, cold urticaria, pressure urticaria, and exercise-induced urticaria). Patients should be subjected to provocative testing for these specific types. The lesions of cholinergic urticaria appear extremely similar to those of $\mathrm{AU}$, but will arise in response to cholinergic stimuli (ie, the rise in the internal core body temperature), such as exercise, sweating, stressful emotions, or eating spicy food. Therefore, cholinergic urticaria will test negative in response to room temperature water challenge. ${ }^{2}$ However, it 
is possible, albeit rare, for patients to have concomitant physical urticarias, which can further complicate the diagnostic process. ${ }^{16,17}$ For example, Bayle et al described a case of a female with $\mathrm{AU}$, dermatographism, and cholinergic urticaria whose cholinergic urticaria responded to oral cetirizine but without resolution of $\mathrm{AU} .{ }^{16} \mathrm{As} \mathrm{AU}$, cholinergic, cold, and heat urticarias can all be induced by exposure to water, it is important to differentiate among these conditions with careful evaluation and appropriate testing (Table 1).

In generating differential diagnoses, one must also consider clinical subtypes of AU. Aquagenic pruritus is a condition in which the patient will develop pruritus without any skin lesions after exposure to water. ${ }^{19}$ Unlike AU, aquagenic pruritus is associated with polycythemia vera and is unresponsive to conventional AU therapies. Salt-dependent AU is a condition with specificity for the salinity of water. As such, the patients will develop urticaria in response to seawater (and $3.5 \% \mathrm{NaCl}$ solution, which is iso-osmolar to seawater), but not tap water or hyperosmolar and nonionic solution such as $20 \%$ glucose. ${ }^{12}$ Several reports describe a localized version of salt-dependent $\mathrm{AU}$ in young females. ${ }^{11,12,15}$ Finally, it is important to ask patients about family history, as there is a reported cohort with familial AU.

\section{Management challenges}

As water is the causative factor for $\mathrm{AU}$, simple avoidance of the offending substance presents as an impractical, at times impossible, task for patients. A multitude of therapies has been used for $\mathrm{AU}$ over the years with varying degrees of efficacy, and we will review the current treatment options here (Table 2).

The urticarial symptoms, such as wheal formation and pruritus, are thought to be mediated, at least partially, by the effects of histamine on the $\mathrm{H}_{1}$ receptor. Therefore, the first-line therapy for $\mathrm{AU}$ generally consists of oral $\mathrm{H}_{1}$ antihistamines. First-generation $\mathrm{H}_{1}$ antihistamines have significant sedative and anticholinergic side effects; these undesirable effects can continue much longer than the therapeutic, antipruritic effect, which only lasts $\sim 4-6$ hours. ${ }^{2}$ For this reason, the newer, second-generation $\mathrm{H}_{1}$ antihistamines with less central nervous system depression but greater duration of action are preferred. While there have been trials demonstrating the greater efficacy of second-generation $\mathrm{H}_{1}$ antihistamines compared to first-generation $\mathrm{H}_{1}$ antihistamines in patients with chronic spontaneous urticaria, there have been no comparable studies to date looking at patients with AU. At best, anecdotal reports show that many patients with $\mathrm{AU}$

Table I Differential diagnosis of aquagenic urticaria

\begin{tabular}{|c|c|c|}
\hline Differential diagnosis & Distinguishing features & Diagnostic testing \\
\hline Aquagenic urticaria & $\begin{array}{l}\text { Distinguish from evaporative cooling and cold } \\
\text { urticaria }\end{array}$ & Wet cloth at room temperature applied for 20 minutes \\
\hline Salt-dependent aquagenic urticaria & $\begin{array}{l}\text { Sea water provokes lesions, with or without } \\
\text { symptoms from tap or distilled water }\end{array}$ & $\begin{array}{l}3.5 \% \mathrm{NaCl} \text { at room temperature soaked in wet cloth } \\
\text { applied for } 20 \text { minutes }\end{array}$ \\
\hline Aquagenic pruritus & Pruritus without the appearance of skin lesions & Wet cloth at room temperature applied for 20 minutes \\
\hline Dermatographism & $\begin{array}{l}\text { Linear, pruritic hives from shear force, the most } \\
\text { common physical urticaria }\end{array}$ & $\begin{array}{l}\text { Linear stroking at various pressures }\left(20-144 \mathrm{~g} / \mathrm{m}^{2}\right) \text { using } \\
\text { dermatographometer, Fric test, or ballpoint pen }\end{array}$ \\
\hline Cholinergic urticaria & $\begin{array}{l}\text { Pinpoint diffuse papular lesions from increase in } \\
\text { internal core body temperature }\end{array}$ & $\begin{array}{l}\text { Exercise challenge to induce sweat for }>10 \text { minutes } \\
\text { or passive warming using hot water bath to raise body } \\
\text { temperature }>1{ }^{\circ} \mathrm{C}\end{array}$ \\
\hline Cold urticaria & $\begin{array}{l}\text { Pruritic wheal and flare from cold contact, up to } \\
\text { one-third of cases of physical urticaria }\end{array}$ & $\begin{array}{l}\text { Placement of ice water in } 50 \mathrm{~mL} \text { beaker for } \mathrm{I}-10 \\
\text { minutes, cold hand immersion for } 5 \text { minutes, total body } \\
\text { cold exposure, evaporative cooling }\end{array}$ \\
\hline Delayed pressure urticaria & $\begin{array}{l}\text { Pruritus, swelling, and pain } 4-8 \text { hours after exposure } \\
\text { may be associated with systemic symptoms of fatigue } \\
\text { and arthralgia }\end{array}$ & $\begin{array}{l}100 \mathrm{~g} / \mathrm{m}^{2} \text { of pressure for } 5-180 \text { seconds on the forearm } \\
\text { using a dermatographometer or } 15 \mathrm{lb} \text { weight bearing on } \\
\text { the shoulder or the lower leg for } 15-20 \text { minutes }\end{array}$ \\
\hline Exercise-induced urticaria & $\begin{array}{l}\text { Not induced by passive warming, larger lesions often } \\
\text { associated with systemic symptoms }\end{array}$ & Exercise challenge as above \\
\hline Local heat urticaria & Reaction limited to area of exposure & $\begin{array}{l}\text { Placement of hot water }\left(45^{\circ} \mathrm{C}-50^{\circ} \mathrm{C}\right) \text { in beaker for } \mathrm{I}-10 \\
\text { minutes }\end{array}$ \\
\hline Solar urticaria & $\begin{array}{l}\text { Immediate reaction to UV and visible light, resolves } \\
\text { within } 24 \text { hours, distinguish from polymorphous light } \\
\text { eruption }\end{array}$ & $\begin{array}{l}\text { UVA, UVB, and visible light stimulation of variable } \\
\text { intensity to establish minimal urticarial dose }\end{array}$ \\
\hline Vibratory angioedema & Erythema and swelling beyond provocation site & Vortex vibratory stimulation for 4 minutes at $2,500 \mathrm{rpm}$ \\
\hline
\end{tabular}

Note: Adapted from Komarow HD, Arceo S, Young M, Nelson C, Metcalfe DD. Dissociation between history and challenge in patients with physical urticaria. J Allergy Clin Immunol Pract. 2014;2(6):786-790. Copyright 2014, with permission from Elsevier. ${ }^{18}$

Abbreviation: UV, ultraviolet. 
Table 2 Therapeutic options for aquagenic urticaria

\begin{tabular}{|c|c|c|}
\hline Therapeutic options & Line of therapy/notes & Proposed mechanism \\
\hline $\begin{array}{l}\text { Nonsedating, second-generation } \mathrm{H}_{1} \text { antihistamines } \\
\text { (eg, cetirizine) }\end{array}$ & $\begin{array}{l}\text { First line at standard dose, second line consider } \\
\text { dose increase up to fourfold }\end{array}$ & $\begin{array}{l}\text { Antagonism or inverse agnosim of } \mathrm{H}_{1} \\
\text { receptor, preventing histamine effects }\end{array}$ \\
\hline First-generation $\mathrm{H}_{1}$ antihistamines (eg, hydroxyzine) & Third line & $\begin{array}{l}\text { Antagonism or inverse agnosim of } \mathrm{H}_{1} \\
\text { receptor, preventing histamine effects }\end{array}$ \\
\hline $\mathrm{H}_{2}$ antihistamines (eg, cimetidine) & Third line & $\begin{array}{l}\text { Unclear in urticaria, may have small additive } \\
\text { effect with } \mathrm{H}_{1} \text { antihistamines }\end{array}$ \\
\hline Acetylcholine antagonists (eg, scopolamine) & Adjuvant with $\mathrm{H}_{1}$ antihistamines & May prevent histamine release \\
\hline Phototherapy (eg, psoralen plus UVA, UVB) & Adjuvant with oral therapy or second-line alone & $\begin{array}{l}\text { Reduction of mast cell activity, reactive } \\
\text { thickening of the epidermis }\end{array}$ \\
\hline Topical barrier creams (eg, petrolatum) & First line or adjuvant & $\begin{array}{l}\text { Hydrophobic effect prevents water } \\
\text { penetration into skin }\end{array}$ \\
\hline Anabolic androgenic steroid (eg, stanozolol) & Case-specific, used in HIV patient with AU & Increases $\mathrm{Cl}$ esterase inhibitor synthesis \\
\hline $\begin{array}{l}\text { Selective serotonin reuptake inhibitors (eg, } \\
\text { fluoxetine) }\end{array}$ & $\begin{array}{l}\text { Case-specific, used in patient with } \\
\text { extracutaneous symptom of } A U\end{array}$ & Unknown \\
\hline
\end{tabular}

Note: Adapted from McGee JS, Kirkorian AY, Pappert AS, Milgraum SS. An adolescent boy with urticaria to water: Review of current treatments for aquagenic urticaria. Pediatr Dermatol. 2014;3 (I): I I6-II7. Copyright 20II Wiley Periodicals, Inc. ${ }^{22}$

Abbreviations: $\mathrm{AU}$, aquagenic urticaria; HIV, human immunodeficiency virus, UV, ultraviolet.

fail to achieve symptomatic control with oral antihistamines alone. . $^{1,3-5,20}$

There is even less data supporting the use of $\mathrm{H}_{2}$ antihistamines in treatment of $\mathrm{AU} . \mathrm{H}_{2}$ receptors are generally considered not to be involved in the pathogenesis of urticaria. However, in one study, $\mathrm{H}_{2}$ antihistamines in combination with $\mathrm{H}_{1}$ antihistamines have shown some effect at further reducing the wheal response in patients with dermatographism, albeit without any added symptomatic relief. ${ }^{21}$ Therefore, addition of $\mathrm{H}_{2}$ antihistamines to $\mathrm{H}_{1}$ antihistamines can be considered for the $\mathrm{H}_{1}$ antihistamine-resistant cases of AU. Moreover, anticholinergics, such as scopolamine, can also be considered as an adjuvant therapy with $\mathrm{H}_{1}$ antihistamines to reduce the urticarial response in certain cases. ${ }^{14}$

Therapies with topical barriers have shown promising results with better safety profiles compared to oral therapies. Application of oil-in-water emulsions and petrolatum containing creams prior to bathing or other exposure to water has been shown to be effective at reducing or completely eliminating urticaria in some patients. ${ }^{16,22}$ This option should be tried first, especially in pediatric patients, to prevent the potential side effects of using antihistamines.

When oral and topical therapies are inadequate, there may be a role for phototherapy, including Psoralens ultraviolet radiation $\mathrm{A}$ and ultraviolet radiation $\mathrm{B}$, which have been reported to resolve symptoms of AU in a few cases. ${ }^{23,24}$ Psoralens ultraviolet radiation $A$ has also been used in combination with antihistamine therapy with good response. ${ }^{25}$ The proposed mechanisms of phototherapy in the treatment of AU include possible reduction of mast cell activity and reactive thickening of the epidermis, leading to decreased water penetration. ${ }^{3}$
Finally, there are case reports supporting the use of stanozolol and selective serotonin reuptake inhibitors in the treatment of AU. Stanozolol is an anabolic steroid without significant androgenic side effects; it has been shown to increase the levels of normal $\mathrm{C} 1$ esterase inhibitors in the management of hereditary angioedema. In one male patient with AU and associated systemic symptoms, $10 \mathrm{mg}$ of stanozolol per day was successful at controlling his symptoms. ${ }^{8}$ Another patient with migraine-like headache upon exposure to water along with urticaria was able to achieve symptomatic control with the addition of a selective serotonin reuptake inhibitor to her medication regimen of antihistamines and anticholinergics. ${ }^{26}$ This raises an interesting possibility of serotonin involvement in the pathogenesis of AU.

\section{Conclusion}

While water may be a seemingly innocuous substance to most of us, there are patients who suffer from side effects of exposure to water. A clinical history of hives in response to water exposure, as well as a positive result of a water challenge test, are keys to diagnosing AU. It is critical to differentiate $\mathrm{AU}$ from other physical urticarias. Therefore, careful evaluation is necessary to rule out other physical stimuli that can mimic the effects of water alone. Patients may need to undergo other tests described in Table 1, depending on the clinical scenario, for a clinician to arrive at the diagnosis of AU.

There is still room for improvement in understanding the mechanism of AU, which could lead to more evidencebased, efficacious treatment strategies for patients. At this time, however, the cornerstone therapy for these patients is 
nonsedating, second-generation $\mathrm{H}_{1}$ antihistamines. While there are several therapeutic options currently available, including other oral agents, topical agents, and phototherapy, there is a lack of strong evidence of their effectiveness. Some patients may be refractory to the medical management described earlier and still need to rely on minimizing water exposure by limiting bathing time and avoiding certain water-based activities.

\section{Future directions}

A familial case of AU associated with Bernard-Soulier syndrome (with a known genetic locus) represents a potential avenue for genetic linkage studies that may uncover the genomic alterations involved in this disease. ${ }^{7}$ More research is certainly needed to delineate the pathogenesis of $\mathrm{AU}$, which will in turn help us develop effective therapies for AU. A large-scale study will be instrumental in this effort, yet has been difficult to execute due to the limited number of $\mathrm{AU}$ patients reported thus far. It is possible that $\mathrm{AU}$ is underrecognized and under reported in the general population. By raising awareness of this condition among health care providers, it may be possible to identify a larger group of patients to assist in further study.

\section{Disclosure}

The authors report no conflicts of interest in this work.

\section{References}

1. Shelley WB, Rawnsley HM. Aquagenic urticaria: contact sensitivity reaction to water. JAMA. 1964;189:895-898.

2. Zuberbier T, Aberer W, Asero R, et al. The EAACI/GA2LEN/EDF/ WAO Guideline for the definition, classification, diagnosis, and management of urticaria: the 2013 revision and update. Allergy. 2014;69(7): 868-887.

3. Luong K, Nguyen L. Aquagenic urticaria: report of a case and review of the literature. Ann Allergy Asthma Immunol. 1998;80(6):483-485.

4. Arıkan-Ayyıldız Z, Işık S, Cağlayan-Sözmen S, Karaman O, Uzuner N. Cold, cholinergic and aquagenic urticaria in children: presentation of three cases and review of the literature. TurkJ Pediatr. 2013;55(1):94-98.

5. Kai AC, Flohr C. Aquagenic urticaria in twins. World Allergy Organ J. 2013;6(1):2.

6. Treudler R, Tebbe B, Steinhoff M, Orfanos CE. Familial aquagenic urticaria associated with familial lactose intolerance. J Am Acad Dermatol. 2002;47(4):611-613.
7. Pitarch G, Torrijos A, Martínez-Menchón T, Sánchez-Carazo JL, Fortea JM. Familial aquagenic urticaria and bernard-soulier syndrome. Dermatology. 2006;212(1):96-97.

8. Fearfield LA, Gazzard B, Bunker CB. Aquagenic urticaria and human immunodeficiency virus infection: treatment with stanozolol. $\mathrm{Br} \mathrm{J}$ Dermatol. 1997;137:620-622.

9. Ozkaya E, Elinç-Aslan MS, Yazici S. Aquagenic urticaria and syncope associated with occult papillary thyroid carcinoma and improvement after total thyroidectomy. Arch Dermatol. 2011;147(12):1461-1462.

10. Tkach JR. Aquagenic urticaria. Cutis. 1981;28:462-463.

11. Gallo R, Campisi C, Agnoletti A, Parodi A. Aquagenic urticaria recurring after epilation and contact with sea water. Contact Dermatitis. 2015; 73(5):313-324.

12. Gallo R, Gonçalo M, Cinotti E, Parodi A. Localized salt-dependent aquagenic urticaria: a subtype of aquagenic urticaria? Clin Exp Dermatol. 2013;38(7):754-757.

13. Czartnetzki BM, Breetholt KH, Traupe H. Evidence that water acts as a carrier for an epidermal antigen in aquagenic urticaria. $J$ Am Acad Dermatol. 1986; 15:623-627.

14. Sibbald RG, Black AK, Eady RA, James M, Greaves MW. Aquagenic urticaria: evidence of cholinergic and histaminergic basis. $\mathrm{Br} \mathrm{J}$ Dermatol. 1981;105(3):297-302.

15. Gallo R, Cacciapuoti M, Cozzani E, Guarrera M. Localized aquagenic urticaria dependent on saline concentration. Contact Dermatitis. 2001;44:110-111.

16. Bayle P, Gadroy A, Messer L, Bazex J. Localized aquagenic urticaria: efficacy of a barrier cream. Contact Dermatitis. 2003;49(3):160-161.

17. Mathelier-Fusade P, Aissaoui M, Chabane MH, Mounedji N, Leynadier F. Association of cold urticaria and aquagenic urticaria. Allergy. 1997; 52(6):678-679.

18. Komarow HD, Arceo S, Young M, Nelson C, Metcalfe DD. Dissociation between history and challenge in patients with physical urticaria. J Allergy Clin Immunol Pract. 2014;2(6):786-790.

19. Bircher AJ, Meier-Ruge W. Aquagenic pruritus. Water-induced activation of acetylcholinesterase. Arch Dermatol. 1988;124(1):84-89.

20. Staevska M, Gugutkova M, Lazarova C, et al. Night-time sedating H1-antihistamine increases daytime somnolence but not treatment efficacy in chronic spontaneous urticaria: a randomized controlled trial. Br J Dermatol. 2014;171(1):148-154.

21. Sharpe GR, Shuster $\mathrm{S}$. In dermographic urticaria $\mathrm{H} 2$ receptor antagonists have a small but therapeutically irrelevant additional effect compared with H1 antagonists alone. Br J Dermatol. 1993;129(5):575-579.

22. McGee JS, Kirkorian AY, Pappert AS, Milgraum SS. An adolescent boy with urticaria to water: review of current treatments for aquagenic urticaria. Pediatr Dermatol. 2014;31(1):116-117

23. Parker RK, Crowe MJ, Guin JD. Aquagenic urticaria. Cutis. 1992;50(4) 283-284.

24. Juhlin L, Malmros-Enander I. Familial polymorphous light eruption with aquagenic urticaria: successful treatment with PUVA. Photodermatol. 1986;3(6):346-349.

25. Martínez-Escribano JA, Quecedo E, De la Cuadra J, Frías J, SánchezPedreño P, Aliaga A. Treatment of aquagenic urticaria with PUVA and astemizole. J Am Acad Dermatol. 1997;36(1):118-119.

26. Baptist AP, Baldwin JL. Aquagenic urticaria with extracutaneous manifestations. Allergy Asthma Proc. 2005;26(3):217-220.
Journal of Asthma and Allergy

\section{Publish your work in this journal}

The Journal of Asthma and Allergy is an international, peer-reviewed open access journal publishing original research, reports, editorials and commentaries on the following topics: Asthma; Pulmonary physiology; Asthma related clinical health; Clinical immunology and the immunological basis of disease; Pharmacological interventions and

\section{Dovepress}

new therapies. This journal is included in PubMed. The manuscript management system is completely online and includes a very quick and fair peer-review system, which is all easy to use. Visit http://www. dovepress.com/testimonials.php to read real quotes from published authors. 